\section{Autonomous Goal Striving Promotes a Nonlimited Theory About Willpower}

\author{
Vanda Sieber', Lavinia Flückiger ${ }^{2}$, Jutta Mata ${ }^{2}$, \\ Katharina Bernecker ${ }^{3}$, and Veronika Job ${ }^{4}$
}

Personality and Socia

Psychology Bulletin

2019, Vol. 45(8) I 295-1307

(C) 2019 by the Society for Personality and Social Psychology, Inc

Article reuse guidelines:

sagepub.com/journals-permissions

DOI: $|0.1| 77 / 0|46| 6721882092$ |

journals.sagepub.com/home/pspb

(S)AGE

\begin{abstract}
People who believe that willpower is not limited exhibit higher self-regulation and well-being than people who believe that willpower is a limited resource. So far, only little is known about the antecedents of people's beliefs about willpower. Three studies examine whether autonomous goal striving promotes the endorsement of a nonlimited belief and whether this relationship is mediated by vitality, the feeling of being awake and energetic. Study I $(n=208)$ showed that autonomous goal striving predicts a change in willpower beliefs over 4 months and that this change is mediated by vitality. Study 2 ( $n=92$ ) replicated this finding using experience sampling assessments of vitality. Experimental Study $3(n=243)$ showed that inducing an autonomous mind-set enhances people's endorsement of a nonlimited belief by fostering vitality. The studies support the idea that what people believe about willpower depends, at least in part, on recent experiences with tasks as being energizing or draining.
\end{abstract}

\title{
Keywords
}

autonomy, vitality, implicit theories, willpower, self-regulation

Received January 17, 2018; revision accepted November 21, 2018

Previous research suggests that successful self-regulation and goal striving in the face of high demands depend on people's beliefs - or implicit theories - about the nature of willpower (Job, Dweck, \& Walton, 2010; Job, Walton, Bernecker, $\&$ Dweck, 2015). Previous research showed that people who believe or are led to believe that willpower is a limited resource (limited theory) display impaired self-control on consecutive tasks. In contrast, people who believe that willpower is not a limited resource but a capacity that remains intact (nonlimited theory) sustain their level of performance regardless of previous self-control exertion (Clarkson, Otto, Hirt, \& Egan, 2016; Job et al., 2010; Miller et al., 2012).

As of yet, only little is known about the antecedents of people's beliefs about willpower. Why do people within the same social and cultural context, like students enrolled at the same university, have such different ideas about the nature of the capacity for self-control? In the present research, we suggest that people's most salient experiences in everyday life have an impact on which theory they hold. More concretely, we propose that the amount of vitality people experience when they work on demanding tasks affects their theories about willpower. Previous research suggests that people feel high levels of vitality when they strive for demanding goals autonomously (Kasser \& Ryan, 1999; Nix, Ryan, Manly, \& Deci, 1999; Ryan \& Frederick, 1997; Sheldon, Ryan, \& Reis, 1996). Connecting the line of research on autonomous goal striving with research on willpower theories, we suggest that autonomous goal striving, by being accompanied by feelings of vitality and energy, promotes the endorsement of a nonlimited theory about willpower.

\section{Implicit Theories About Willpower}

Research on implicit theories about willpower has challenged the metabolic and resource-oriented strength model of self-control (Baumeister, Bratslavsky, Muraven, \& Tice, 1998; Muraven \& Baumeister, 2000). The strength model of self-control states that controlling oneself consumes a limited resource. Accordingly, repeated acts of self-control lead to a state of reduced self-control capacity called egodepletion. This assumption has been tested in studies where participants first worked on a task that either did or did not require self-control. A second task assessed participants'

\footnotetext{
'University of Zurich, Switzerland

${ }^{2}$ University of Mannheim, Germany

${ }^{3}$ Leibniz-Institut für Wissensmedien, Tübingen, Germany

${ }^{4}$ Technical University of Dresden, Germany

Corresponding Author:

Vanda Sieber, Institute of Education, University of Zurich, Freiestrasse 36, Zurich 8032, Switzerland.

Email: vanda.sieber@ife.uzh.ch
} 
subsequent self-control performance (Baumeister et al., 1998). The ego-depletion effect is thereby a pattern of results where participant who previously exerted self-control perform worse afterward as compared with participants in a control condition. ${ }^{1}$

Several studies found that motivational processes are involved in the occurrence of ego-depletion (e.g., Muraven $\&$ Slessareva, 2003). Based on these findings, Job and colleagues (2010) suggested that the ego-depletion effect is not caused by a lack of metabolic resources, but rather depends on what people believe about the nature of willpower. In a series of laboratory experiments, they showed that only the self-control performance of people who believe that willpower relies on a limited resource gets impaired by the previous exertion of self-control. Conversely, the performance of people who believe that willpower is not limited remains stable over a series of demanding self-control tasks (Salmon, Adriaanse, Vet, Fennis, \& DeRidder, 2014). These findings suggest that changes in motivational variables may explain the failure of self-control across multiple tasks. Accordingly, research on implicit theories about willpower is in line with and supports recently proposed motivational accounts of ego-depletion (Inzlicht, Schmeichel, \& Macrae, 2014; Kurzban, Duckworth, Kable, \& Myers, 2013; Molden, Hui, \& Scholer, 2016; Molden et al., 2012).

Research has also accumulated evidence demonstrating the positive effects of a nonlimited theory about willpower on various outcomes in everyday life, including following a healthier diet, less procrastination (Bernecker \& Job, 2015; Job et al., 2010; Job, Walton et al., 2015), and earning higher grades in the face of high academic load (Job, Walton et al., 2015). Yet little is known about possible antecedents of people's implicit theories about willpower. One line of research has investigated cultural differences in beliefs about willpower. It suggests that cultural background (e.g., Western vs. Indian cultural context) is one factor shaping people's implicit theories about willpower (Savani \& Job, 2017). However, within each cultural context there is still considerable variance in implicit theories about willpower. Previous research assessing homogeneous samples, such as students enrolled at the same university, has found large individual differences (e.g., Bernecker, Herrmann, Brandstätter, \& Job, 2017; Job, Walton et al., 2015).

The present research identifies an experience-based factor that affects a person's beliefs about the nature of willpower. Drawing on the basic idea that beliefs are influenced by people's own experiences (Clandinin, 1986; Richardson, 1996), we propose that experiences during goal striving shape whether people believe that willpower is a limited or a rather nonlimited resource. More specifically, we propose that if people predominantly strive for goals autonomously ("wantto goals"), they experience feelings of energy and vitality which in turn support the belief that willpower is not limited. In sum, we propose that one's recent experiences with demanding tasks affects which theory is currently available to an individual.

\section{Goal Motivation}

Goals are anticipations of future states that are of importance to an individual (Brunstein \& Maier, 2002; Fishbach \& Ferguson, 2007). They reflect what people want to attain and what they want to avoid in their everyday lives. Previous research has suggested that people's underlying motivation, that is, why people strive for a goal, critically affects how they feel and how they regulate goal striving. For example, one person engages in physical activity for the mere enjoyment it provides to her, whereas another person is supposed to exercise for medical reasons. In the first case, the person is said to pursue a "want-to" or autonomous goal (also called "self-concordant"; Sheldon \& Elliot, 1999), whereas in the latter case the person strives for a "have-to" or controlled goal (Inzlicht et al., 2014; Milyavskaya, Inzlicht, Hope, \& Koestner, 2015).

The two different types of goals lead to different affective and motivational consequences. Controlled behavior emerging from the pursuit of have-to goals is prone to conflict and, accordingly, associated with tension, reluctance, and aversion (Ryan \& Deci, 2008; Sheldon \& Kasser, 1995; Thayer \& Moore, 1972). In contrast, autonomous goals are by definition associated with enjoyment, interest, and personal significance (e.g., Milyavskaya et al., 2015). Therefore, they are an important source of motivation and energy. The positive feelings of being alive and energetic while working on autonomous goals have been described as vitality (Frederick \& Ryan, 1993; Nix et al., 1999; Ryan \& Frederick, 1997). Importantly, vitality is not a reflection of the caloric energy at one's disposal. It represents a subjective feeling that energy is available to the self (Hope, Milyavskaya, Holding, \& Koestner, 2016; Ryan \& Frederick, 1997; Thayer, 1997).

Several field studies have confirmed the assumption that autonomous motivation leads to enhanced feelings of vitality. For example, students (Sheldon et al., 1996), people participating in a weight-loss program (Ryan \& Frederick, 1997, Study 5), and residents in a nursing care environment for older adults (Kasser \& Ryan, 1999) reported experiencing higher vitality when they pursued want-to goals as compared with have-to goals. These findings have been further corroborated by experimental research showing that vitality was enhanced when participants did well on a task they worked on autonomously (Nix et al., 1999). In sum, research demonstrates that people feel energized when working toward autonomous goals compared with controlled goals.

\section{The Present Research}

In the present research, we propose that the energizing experience during goal striving while working on an autonomous goal contributes to the endorsement of a nonlimited theory about willpower. People who strive for their personal goals with autonomous motivation will be more likely to experience that, although a task is difficult and challenging, they 
have the energy to stay focused for the required period. The frequent experience of high vitality during autonomous goal striving should promote a more nonlimited theory about willpower.

Three studies examined whether striving for autonomous goals promotes the endorsement of a nonlimited theory about willpower, and whether subjective feelings of vitality mediate this relationship. Study 1 tested longitudinally whether striving for autonomous personal goals in different domains predicts a change in willpower beliefs toward a nonlimited theory and whether vitality explains this relationship. Study 2 provides a more valid day-to-day measure of vitality using experience sampling. Finally, using an experimental design, Study 3 tested the causal relationship between striving for an autonomous goal, vitality, and implicit theories about willpower. ${ }^{2}$

\section{Study I}

Study 1 tested whether the perceived autonomy of personal goals predicts a change in implicit theories toward a nonlimited theory about willpower. Willpower theories and vitality were measured twice, 4 months apart. At the beginning of the study, participants provided information on six personal goals they intended to pursue during the upcoming months. For each goal, participants answered questions on goal motivation. We expected that the more participants were striving for their personal goals out of autonomous reasons, the more vitality they would experience during that period. This, in turn, would predict a change toward a nonlimited theory about willpower.

\section{Method}

Participants and procedure. A sample of German-speaking participants was recruited with the assistance of the market research institution Respondi AG (http://www.respondi .com/en/) to participate in an online study on "well-being, attitudes, and personal goals" in exchange for 3 euros (i.e., about US\$4). Out of 338 persons who clicked on the link to the study, $n=277$ completed the first questionnaire. Four months later, participants were invited to fill in a second questionnaire to earn an additional 3 euros. A total of $n=$ 208 (94 females and 114 males; $M_{\text {age }}=52.89, S D=14.98$, range: $19-58$ years) completed both questionnaires. Participants who dropped out of the study did not differ in any measure of interest (i.e., implicit theories about willpower, vitality, and autonomous goal striving) assessed at Time 1 from participants who continued with the study, $t \mathrm{~s}<|1.47|$. As this set of studies was the first to test the hypothesized relationship, sensitivity analyses were conducted with MedPower (Kenny, 2017). The analysis revealed that a sample size of $n=208$ would require an indirect effect of $\beta=0.05$ to reach $80 \%$ power. $^{3}$

At the beginning of the first questionnaire, participants gave their informed consent and reported demographic information. Next, participants answered questions concerning their theories about willpower, their vitality, and their personal goals. In a second measurement, all variables were assessed once again. ${ }^{4}$ The questionnaires were in German. Please consult the supplementary material for the complete documents.

Autonomous goal striving. An idiographic approach was used to measure autonomous motivation for personal goals. Participants were asked to list personal goals in the domains of work/education, social relationships, and leisure activities (Emmons, 1986; Sheldon, 2002; Sheldon \& Elliot, 1999). For each domain, they were asked to list two goals (six in total). Participants were asked, for example, to describe "a personal goal you want to pursue in the domain of work and education." Examples of responses include "pass my bachelor's degree" or "make more money." Participants indicated how much they strove for each goal for autonomous (intrinsic, identified) or for controlled (external, introjected) reasons to measure autonomy of self-set goals (see Sheldon \& Elliot, 1999, for a similar procedure). Two statements reflected autonomous motivation ("I pursue this goal because it gives me pleasure and enjoyment" and "I pursue this goal because I believe it is important") and two items reflected more controlled motivation ("I pursue this goal because I would feel bad [guilty, ashamed, anxious] otherwise" and "I pursue this goal because it has been requested or the situation requires it"); statements were rated on a 6-point Likert-type scale from $1=$ totally disagree to $6=$ totally agree. As in previous research (Sheldon, Ryan, Deci, \& Kasser, 2004), a score reflecting relative autonomy was computed for each participant by summing up the autonomous goal striving scores and subtracting the controlled goal striving scores for each goal (T1: $M=5.09, S D=$ 2.67; T2: $M=5.00, S D=2.85$ ).

Vitality was measured with four items from the Multidimensional Mood Questionnaire (MDMQ, Steyer, Schwenkmezger, Notz, \& Eid, 1997). Participants rated how well each adjective ("rested," "energetic," "tired" [reverse scored] and "exhausted" [reverse scored]) reflected how they had felt lately on a scale from $1=$ not at all to $6=$ very $m$ much (T1: $\alpha=.85, M=3.74, S D=1.12$; T2: $\alpha=.87, M=3.79$, $S D=1.13)$.

Implicit theories about willpower were measured using a short version of the German translation of the Implicit Theories about Willpower Scale (four items; Job et al., 2010). Participants answered items such as "After a strenuous mental activity, my energy is depleted and I must rest to get it refueled again" (limited theory) and "My mental stamina fuels itself; even after strenuous mental exertion, I can continue doing more of it" (nonlimited theory) on a scale from $1=$ strongly disagree to $6=$ strongly agree. Items concerning the limited theory were reverse-scored, hence a high value represents a higher agreement with a nonlimited theory (T1: $\alpha=.85, M=3.66, S D=1.12$; T2: $\alpha=.88$, $M=3.77, S D=1.18)$. 
Table I. Pearson Correlations and Descriptive Statistics, Study I.

\begin{tabular}{|c|c|c|c|c|c|c|c|}
\hline Variables & I & 2 & 3 & 4 & 5 & M & $S D$ \\
\hline I. Autonomous goal striving (TI) & - & & & & & 5.09 & 2.67 \\
\hline 2. Vitality $(\mathrm{TI})$ & $.38 * * *$ & - & & & & 3.74 & 1.12 \\
\hline 3. Nonlimited theory about willpower (TI) & $.37 * * *$ & $.40 * * *$ & - & & & 3.66 & 1.12 \\
\hline 4. Autonomous goal striving (T2) & $.69 * * *$ & $.36 * * *$ & $.36^{* * *}$ & - & & 5.00 & 2.85 \\
\hline 5. Vitality $(\mathrm{T} 2)$ & $.39 * * *$ & $.60 * * *$ & $.40 * * *$ & $.39 * * *$ & - & 3.79 & 1.13 \\
\hline 6. Nonlimited theory about willpower (T2) & $.38 * * *$ & $.40 * * *$ & $.67^{* * *}$ & $.38 * * *$ & $.43 * * *$ & 3.77 & 1.18 \\
\hline
\end{tabular}

Note. $\mathrm{TI}=$ first measurement; $\mathrm{T} 2=$ second measurement. $* * * p<.001$.

\section{Results}

Preliminary analyses and descriptive statistics are presented in Table 1 . The stability over the period of 4 months was high for autonomous goal striving $(r=.69, p<.001)$, vitality $(r=.60, p<.001)$, and willpower theories $(r=.67$, $p<.001$ ). Replicating previous research, autonomous goal striving was significantly correlated with vitality within each measurement (T1: $r=.38, p<.001 ; \mathrm{T} 2: r=.39, p<.001$ ). In line with our hypothesis, implicit theories about willpower were significantly correlated with autonomous goal striving (T1: $r=.37, p<.001 ; \mathrm{T} 2: r=.38, p<.001$ ) and vitality (T1: $r=.40, p<.001 ; \mathrm{T} 2: r=.43, p<.001$ ), suggesting that people with a nonlimited theory pursued their goals for more autonomous reasons and experienced more vitality.

Longitudinal analyses. To test our hypothesis that autonomous goal striving would predict a change in willpower theories toward a nonlimited theory, we conducted a hierarchical regression analysis of willpower theories at $\mathrm{T} 2$ controlling for willpower theories at $\mathrm{T} 1$ in the first block. Autonomous goal striving at T1 was entered in the second block. Autonomous goal striving significantly predicted $\mathrm{T} 2$ willpower theories, $\beta=0.15, b=.07$, se $=0.02, t(205)=2.73, p=.007$, $95 \%$ confidence interval $\left(\mathrm{C}\right.$ I) $[0.02,0.12], \Delta R^{2}=.02, f^{2}=$ 0.02 , supporting our hypothesis. The more autonomously participants pursued their personal goals at $\mathrm{T} 1$, the more they endorsed a nonlimited theory about willpower at $\mathrm{T} 2$.

Next, we ran exploratory analyses to test the opposite direction of the effect. Would a nonlimited willpower theory predict a change in autonomous goal striving? We ran a hierarchical regression predicting $\mathrm{T} 2$ autonomous goal striving with $\mathrm{T} 1$ willpower theories controlling for autonomous goal striving at T1: The more participants endorsed a nonlimited theory about willpower, the more likely they reported autonomous goal striving at $\mathrm{T} 2, \beta=0.12, b=.31, s e=0.14, t(204)=2.27$, $p=.024,95 \%$ CI $[0.04,0.58], \Delta R^{2} \stackrel{b}{=} .01, f^{2}=0.01$.

Mediation analysis. We hypothesized that autonomous goal striving at $\mathrm{T} 1$ predicts implicit theories about willpower at $\mathrm{T} 2$ via enhanced feelings of vitality at $\mathrm{T} 2$. To test this hypothesis, we used PROCESS (Preacher \& Hayes, 2004, see Figure 1). We controlled for implicit theories at T1, $b=0.59$, $s e_{b}=0.06, p<.001,95 \%$ CI [0.47, 0.72]. Results indicate that autonomous goal striving at $\mathrm{T} 1$ was a significant predictor of vitality at T2, $b=0.16, s e_{b}=0.03, p<.001,95 \% \mathrm{CI}$ $[0.11,0.22]$, and that vitality at T2 was a significant predictor of implicit theories about willpower at T2, $b=0.18, s e_{b}=$ $0.06, p=.005,95 \%$ CI $[0.06,0.31]$. The significance of the indirect effect was tested using 5,000 bias-corrected bootstrapped samples. The analyses revealed a significant indirect effect of autonomous goal striving on implicit theories about willpower, $\beta=0.07, b=0.03,95 \%$ CI $[0.01,0.06]$. Furthermore, autonomous goal striving was no longer a predictor of implicit theories about willpower once vitality was controlled for, $b=0.05, s e_{b}=.03, p=.126,95 \%$ CI $[-0.01$, $0.10]^{5}$

We also conducted an exploratory mediation analysis for the reverse effect. First, we controlled for autonomous goal striving at T1, $b=0.65, s e_{b}=0.07, p<.001,95 \% \mathrm{CI}[0.51,0.79]$. Results indicate that the implicit theories about willpower at T1 were a significant predictor of vitality at $\mathrm{T} 2, b=0.40, s e_{b}=$ $0.07, p<.001,95 \% \mathrm{CI}[0.26,0.54]$, but vitality at T2 did not significantly predict autonomous goal striving at $\mathrm{T} 2, b=0.29$, $s e_{b}=0.16, p=.081,95 \% \mathrm{CI}[0.04,0.61]$. The indirect effect was not significant, $b=0.11,95 \%$ CI [-0.00, 0.27].

\section{Discussion}

The results of Study 1 support the assumption that people who strive for personal goals autonomously experience higher levels of vitality, which makes them endorse a more nonlimited theory about willpower over time. The longitudinal analyses showed that also people with a nonlimited theory about willpower tend to report more autonomous goal striving over time. Hence, the relationship between autonomous goal striving and a nonlimited willpower theory seems to be reciprocal. However, the indirect effect was not significant in the reverse mediation model. Thus, the reverse relationship must be mediated by other variables than vitality.

\section{Study 2}

Study 1 provides initial evidence for the relationship between striving for autonomous goals, vitality, and willpower theories 


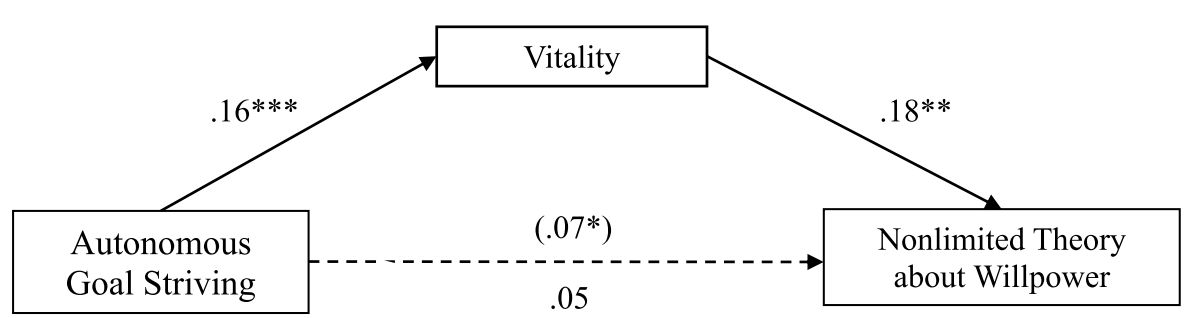

Figure I. Regression coefficients for the relationship between autonomous goal striving and nonlimited theory about willpower in Study I.

Note. The number in parentheses represents the total effect. $*_{p}<.05 . * * p<.01 . * * * p<.001$.

using a heterogeneous community sample and an idiosyncratic approach to personal goals. In Study 2, we sought to test our hypothesis in a more homogeneous student sample in which all participants pursued one single goal: passing difficult examinations to advance in their studies. Furthermore, Study 2 improved the assessment of the mediating variable by assessing vitality using an experience-sampling methodology (ESM, Csikszentmihalyi \& Larson, 1987; Hormuth, 1986). During a total of 20 days, divided into three 1-week assessment blocks (at the beginning, the middle, and the end of the term), participants indicated their momentary level of energy 5 times a day. We hypothesized that students who- at the beginning of the term - indicated that they pursued the goal of passing the final exams for more autonomous reasons, would experience more vitality during the term than students who strived for this goal for extrinsic reasons. We assumed that experiencing more vitality would in turn facilitate the endorsement of a nonlimited theory about willpower.

\section{Method}

Participants and procedure. The participants were first-year undergraduate students who were recruited in an introductory lecture to participate in a study on "learning motivation, mood, and health behavior in the first academic year." The study was part of a larger research project. ${ }^{6}$ The results presented here were collected in two questionnaires, one at the beginning of the term (T1), in March 2016, and one 4 months later after the exams (T2), in June 2016. In addition, 100 experience sampling assessments (ESM, Csikszentmihalyi \& Larson, 1987; Hormuth, 1986) were carried out over the course of 20 days during 3 weeks. The first ESM-week started at the beginning of April after the completion of the first questionnaire (T1), the second ESM-week started 2 weeks later, and the third ESM-week was at the end of the term, 4 weeks after the second ESM-week. The participants were either given 195 Swiss Francs (about US\$200) or course credit in return for taking part at all measurement points. A sample of $N=212$ participants completed the first questionnaire. Of these, $n=92$ also participated in the ESM measurements and completed the T2 questionnaire. Participants who completed at least 10 ESM measurements across the blocks $(M=69.61, S D=19.86)$ were included in the analyses. This final sample consisted of 76 women and 16 men $\left(M_{\text {age }}=21.99, S D_{\text {age }}=4.31\right.$, range: $18-47$ years $)$. Participants who dropped out of the study did not differ in any of the measures of interest at Time 1 from the remaining participants, $t s<|0.53|$. Sensitivity analyses revealed that a sample size of $n=92$ would require an indirect effect of $\beta=$ 0.11 to reach $80 \%$ power. $^{3}$

Autonomous goal striving. Participants were asked to indicate how much autonomy they felt regarding the goal "passing the first-year exams" using the same questions as in Study 1 $(M=1.85, S D=3.11)$.

Vitality was measured at every signal of the ESM measurements using an item from the MDMQ (Steyer et al., 1997) asking participants how fresh they felt right now; original item: "How do you feel right now?" $(1=$ not fresh at all to $7=$ extremely fresh). ${ }^{7}$ The intraclass correlation $\operatorname{ICC}(2)$ value of .92 indicates that individuals can be reliably differentiated in terms of average vitality. Therefore, it was justified to aggregate all the ESM assessments of each participant in a total vitality score $(M=3.95, S D=0.91)$ to test the main research hypotheses.

Implicit theories about willpower were measured as in Study 1 using the brief Implicit Theories about Willpower Scale (four items). Items concerning the limited theory were reverse-scored, leading to high values representing a higher agreement with a nonlimited theory (T1: $\alpha=.80, M=2.94$, $S D=0.77 ; \mathrm{T} 2: \alpha=.81, M=3.43, S D=0.81)$.

\section{Results}

Preliminary analyses and descriptive statistics are presented in Table 2. Vitality was significantly correlated with autonomous goal striving $(r=.27, p=.009)$ and with implicit theories about willpower at Time $2(r=.31, p=.003)$. For the implicit theories about willpower, a weaker stability was found compared with Study $1, r=.18, p=.081$. 
Table 2. Pearson Correlations and Descriptive Statistics, Study 2.

\begin{tabular}{lccccr}
\hline Variables & 1 & 2 & 3 & $M$ & $S D$ \\
\hline I. Autonomous goal striving & - & & & 1.85 & 3.11 \\
2. Implicit theories about willpower (TI) & -.01 & - & & 2.94 & .77 \\
3. Implicit theories about willpower (T2) & .20 & .18 & - & 3.43 & .81 \\
4. Vitality & $.27^{* *}$ & .03 & $.31^{* *}$ & 3.95 & .91 \\
\hline
\end{tabular}

Note. $\mathrm{TI}=$ first measurement; $\mathrm{T} 2=$ second measurement.

$* * p<.0$ l.

Longitudinal analysis. To test whether autonomous goal striving predicts a change in willpower theories, we conducted a hierarchical regression analysis of willpower theories at T2 controlling for willpower theories at T1 in the first block. Autonomous goal striving at T1 was entered in the second block. As a trend, autonomous goal striving predicted T2 willpower theories, $\beta=0.20, b=0.05$, se $e_{b}=0.03, t(89)=$ $1.92, p=.058,95 \%$ CI $[-0.00,0.10], \Delta R^{2}=.04, f^{2}=0.04$. The more autonomously participants pursued their personal goals at T1, the more they endorsed a nonlimited theory about willpower at T2. As we did not ask participants about their motivation to pass the exam at the end of the study (they had taken the exam by then), we had no T2 measurements of autonomous goal striving. Therefore, we could not test the reciprocal effect of willpower theories on autonomous goal striving as in Study 1.

Autonomous goal striving and vitality. Because vitality was measured multiple times for each participant, we applied hierarchical linear modeling (HLM) to test whether autonomous goal striving at T1 predicted higher levels of vitality assessed over the course of the experience-sampling period. Measurement points (Level 1) were nested within participants (Level 2). The model was estimated in $R$ (version 3.3.3, R Core Team, 2017) using the nlme package (Pinheiro, Bates, DebRoy, Sakar, \& Core Team, 2017) and fitted using a maximum likelihood estimation procedure. To estimate the size of the effect, we used the MuMIn package (Barton, 2018).

First, we analyzed the variance structure of vitality and found that $67 \%$ of the variance in vitality can be explained by the individual. The fixed effects model predicting vitality by autonomous goal striving at T1 (z-transformed, which is equivalent to grand-mean centering) showed that autonomous goal striving was positively associated with levels of vitality, $b=0.24$, se $=0.09, t(90)=2.68, p=.009,95 \% \mathrm{CI}$ $[0.06 ; 0.42]$. The random effect of the intercept was $S D=$ 0.80 with a grand mean of $\gamma_{00}=3.77$, suggesting that $68 \%$ of intercepts in vitality were located between 2.97 and 4.57 . In terms of the effect size, analyses of pseudo $R^{2}$ revealed a marginal $R^{2}=.06$ and conditional $R^{2}=.67$, suggesting that $6 \%$ of the variance is explained by the fixed effect of autonomous goal striving and $67 \%$ by both fixed and random factors (i.e., the entire model).
Vitality and implicit theories about willpower. To test whether the most recent experiences of vitality have the largest impact on implicit theories about willpower, we calculated three partial correlations (controlling for baseline assessments of willpower theories). As predicted, the most recent vitality assessments show the strongest correlation with implicit theories about willpower: $r(89)=.24, p=.022, r(87)=.25$ for the first ESM-week of vitality assessments, $p=.018$ for the second week, and $r(86)=.34, p=.001$ for the third ESMweek of vitality assessments.

Mediation analysis. A mediation analysis was conducted (PROCESS, Preacher \& Hayes, 2004, see Figure 2) to test whether the aggregated vitality scores mediate the relationship between autonomous goal striving and a change in implicit theories about willpower. For the analyses concerning the dependent variable, we controlled for implicit theories at T1, $b=0.18, s e_{b}=0.14, p=.18,95 \%$ CI $[-0.09$, 0.46]. Autonomous goal striving at T1 was a significant predictor of vitality during the ESM assessments, $b=0.08$, $s e_{b}=0.03, p=.006,95 \%$ CI $[0.02,0.14]$, and vitality was a significant predictor of implicit theories about willpower at $\mathrm{T} 2, b=0.24, s e_{b}=0.10, p=.020,95 \%$ CI $[0.04,0.44]$. The significance of the indirect effect was tested using 5,000 bias-corrected bootstrapped samples. The analyses revealed a significant indirect effect of autonomous goal striving on implicit theories about willpower, $\beta=0.12, b=0.02,95 \%$ CI $[0.00,0.05]$. As in Study 1, autonomous goal striving did not predict implicit theories about willpower when vitality was controlled for, $b=0.03, s e_{b}=0.03, p=.197,95 \% \mathrm{CI}$ $[-0.02,0.08]$.

\section{Discussion}

Study 2 replicates the results of Study 1, showing that pursuing a goal for a more autonomous reason predicts a shift toward a more nonlimited theory about willpower, which is mediated by vitality. By aggregating several daily measures of vitality, a more precise measurement of vitality was used. Additional analyses show that, on a descriptive level, the most recent experiences of vitality were more strongly associated with a nonlimited theory about willpower. This pattern is consistent with our reasoning that the most salient experiences have the largest impact on people's implicit theories 


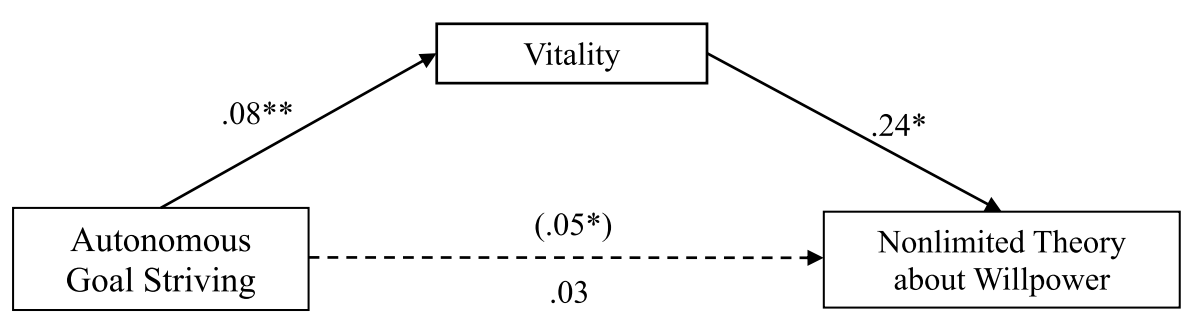

Figure 2. Regression coefficients for the relationship between autonomous goal striving and nonlimited theory about willpower in Study 2.

Note. The number in parentheses represents the total effect. $* p<.05 . * * p<.01$.

about willpower. Moreover, all participants pursued the same goal of passing their intermediate exams, ruling out the possibility that other goal characteristics varying between participants account for the effect.

\section{Study 3}

In Study 3, we manipulated the experience of autonomous goal motivation to further test the causal effect of goal motivation on implicit theories about willpower. Participants were randomly assigned to a condition leading them to adopt either an autonomous motivation mind-set or a controlled motivation mind-set. To achieve this, we asked participants to remember and to put themselves back in a situation in which they had worked on an autonomous goal or a controlled goal. We hypothesized that being reminded of striving for an autonomous goal would enhance their perceived vitality and thus foster the endorsement of a nonlimited theory about willpower.

\section{Method}

Participants and procedure. Three hundred thirteen participants (U.S. residents) clicked on the link on Amazon's Mechanical Turk (MTurk) to participate in a study on how people work on different tasks. Of those, $n=19$ left after signing the informed consent. An additional $n=51$ left after the experimental manipulation. Dropout analysis revealed that dropouts were equally distributed between the autonomy (27 dropouts) and the controlled-motivation condition (24 dropouts), $\chi^{2}(1)=0.39, p=.534$. A total of $n=243$ participants completed the study. The sample ( $44 \%$ females, $M_{a g}$ $\left.=36.50, S D_{a g e}=11.52\right)$ was diverse concerning employment status (163 were working full-time, 50 worked parttime, 19 were looking for work, six had retired, three were full-time students, and two were part-time students). Analyses revealed that a sample size of $n=243$ would require an indirect effect of $\beta=0.04$ to reach $80 \%$ power. ${ }^{3}$

Experimental manipulation of autonomy. After providing demographic information, participants were randomly assigned to the experimental groups. The experimental manipulation either asked participants to imagine working on a task autonomously $(n=117)$ or for controlled reasons $(n=126)$. Participants in the autonomous motivation condition were instructed to think about a mentally demanding task they worked on lately because of the mere enjoyment it provided to them. In contrast, participants in the controlled motivation condition were asked to think about a mentally demanding task they worked on lately because someone else wanted them to or because it was required by the situation. Once they had chosen a situation, participants indicated how mentally demanding the task they worked on had been on a scale ranging from $1=$ not at all to $10=$ very much $(M=8.03, S D=$ 1.47). On the next page, participants were instructed to put themselves back in the situation and to describe the situation with several sentences for $2 \mathrm{~min}$. As in previous research working with similar experimental manipulations, participants were instructed to focus on their thoughts and feelings while working on the task (Schüler, Sheldon, Prentice, \& Halusic, 2016; Sieber, Schüler, \& Wegner, 2016). When the 2 min were over, the "next" button leading to the following page appeared and participants were able to continue whenever they felt they had finished (time in seconds spent writing about the task, $M=196.68, S D=133.34$ ).

Implicit theories about willpower. After the experimental manipulation, implicit theories about willpower were measured using the original six-item scale (Job et al., 2010). Again, items concerning the limited theory were reversescored, so high values represent a higher agreement with a nonlimited theory $(\alpha=.91, M=2.86, S D=1.15){ }^{8}$

Vitality. State level vitality was assessed using the Vitality Scale (Ryan \& Frederick, 1997). ${ }^{9}$ Participants answered the six items describing how they felt while working on the task (e.g., "I felt energized while working on that task"; $1=$ not at all true, $6=$ very true, $\alpha=.90, M=3.67, S D=1.26$ ).

Manipulation check. To assess whether the experimental manipulation had been successful, participants answered four questions referring to the remembered situation on a 6-point scale $(1=$ strongly disagree, $6=$ strongly agree $)$ : "I worked on that task because it gives me pleasure and enjoyment," "I 


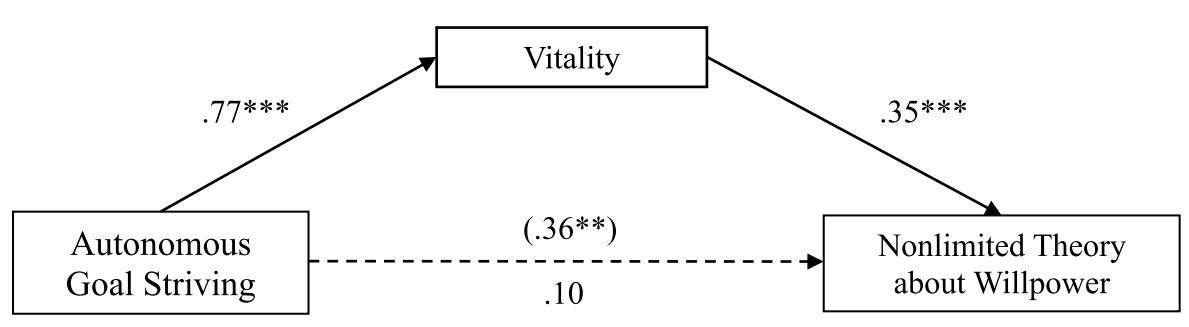

Figure 3. Regression coefficients for the relationship between autonomous goal striving and nonlimited theory about willpower in Study 3.

Note. The number in parentheses represents the total effect.

$* * p<.01$. ***p $<.001$.

worked on that task because I believe it is important," "I worked on that task because I would feel bad (guilty, ashamed, or anxious) otherwise," and "I worked on that task because it is requested or the situation requires it." The relative autonomy index was computed as in Studies 1 and $2(M=1.41$, $S D=4.34){ }^{10}$

In addition, single items assessed success in working on the task ("I was successful in working on that task," $M=$ $5.14, S D=1.15$ ), importance ("This task was very important to me," $M=4.77, S D=1.43$ ), exhaustion ("Doing something for that task exhausted me," $M=3.49, S D=1.68$ ), and reluctance ("I was often not in the mood to do something for that task," $M=3.21, S D=1.65)$. The items were answered on a 6-point scale $(1=$ strongly disagree, $6=$ strongly agree $)$.

\section{Results}

Manipulation check and preliminary analyses. A $t$ test concerning the experimental manipulation $(0=$ controlled, $1=$ autonomous) showed that participants in the autonomy condition experienced significantly more autonomy $(M=3.83$, $S D=3.72)$ compared with participants in the controlledmotivation condition $(M=-0.83, S D=3.62), t(241)=$ $-9.90, p<.001, d=1.27$.

Tasks that participants worked on autonomously $(M=$ $7.95, S D=1.38$ ) were not perceived as being less demanding than tasks participants worked on for controlled reasons $(M=8.10, S D=1.56), t(241)=0.82, p=.415, d=0.10$. In addition, no difference was found concerning importance and success in working on the tasks, $t s<|0.77|$. However, participants in the controlled-motivation condition indicated that they perceived their task to be more exhausting, $t(231.67)$ $=$ 5.61, $p<.001 . d=0.73$. Furthermore, participants assigned to the controlled-motivation condition indicated more strongly that they were often not in the mood to work on the task than did participants in the autonomy condition, $t(241)=5.07, p<.001, d=0.65$.

Testing the hypothesis. As expected, participants in the autonomy condition were more likely to endorse a nonlimited theory about willpower $(M=3.04, S D=1.17)$ compared with participants in the controlled-motivation condition $(M=2.68$, $S D=1.11), t(241)=2.49, p=.014, d=0.32$. Furthermore, the two conditions differed in the strength of experienced vitality. Participants in the autonomy condition reported more vitality $(M=4.06, S D=1.07)$ compared with participants in the controlled-motivation condition $(M=3.30, S D=0.10)$, $t(236.84)=5.00, p<.001, d=1.00$.

Mediation. To test whether vitality mediates the effect of the experimental manipulation on theories about willpower, we ran a mediation analysis using PROCESS (Preacher \& Hayes, 2004, see Figure 3). The experimental manipulation ( $0=$ controlled, $1=$ autonomous $)$ was a significant predictor of vitality, $b=.77$, $s e_{b}=.15, p<.001,95 \%$ CI $[0.46$, 1.07], and vitality was a significant predictor of implicit theories about willpower, $b=.35, s e_{b}=.06, p<.001,95 \% \mathrm{CI}$ $[0.23,0.46]$. The indirect effect of autonomous goal striving on implicit theories about willpower was tested using 5,000 bias-corrected bootstrapped samples. The analyses revealed a significant indirect effect, $b=0.27,95 \%$ CI [0.15, 0.42]. When controlling for vitality, the experimental manipulation was no longer a significant predictor of implicit theories about willpower, $b=0.10, s e_{b}=0.15, p=.504,95 \% \mathrm{CI}$ $[-0.19,0.39]$.

\section{Discussion}

Study 3 complements the first two studies by experimentally testing the causal relationship between striving for an autonomous versus controlled goal and implicit theories about willpower. As expected, participants who thought about a situation in which they had worked on an autonomous goal reported enhanced vitality and a stronger agreement with a nonlimited theory. Conversely, people who thought about a situation in which they were striving for a controlled goal reported less vitality and agreed with a limited theory about willpower. Those findings show that willpower theories can be changed by making people think about recent experiences with strenuous tasks. 


\section{General Discussion}

The present set of longitudinal and experimental studies showed that striving for goals autonomously promotes a nonlimited theory about willpower and that this relationship is explained through the subjective experience of vitality. These findings held for self-set goals across different domains (work/education, social relationships, and leisure activities) in diverse community samples (Study 1 and Study 3 ), as well as with regard to a single goal shared by a more homogeneous group of participants (Study 2).

\section{Theoretical Implications}

Our results show that even if people strive for goals that are similarly difficult and demanding those who do so with a feeling of high autonomy experience more vitality compared with people who pursue these goals because they have to. The finding that striving for an autonomous goal is associated with vitality is in line with previous research (e.g., Nix et al., 1999). Furthermore, our studies demonstrate that this vitalizing experience while striving for a want-to goal fosters the endorsement of a nonlimited theory about willpower. People who experience higher levels of vitality when pursuing their goals have the experience that even if a task is strenuous, they can draw energy from working on it and believe that willpower is a nonlimited resource. On the contrary, when striving for a more controlled goal, people lack this energizing experience and subsequently think that their capacity to exert self-control is highly limited and gets depleted whenever they use it.

Our results imply that theories about willpower, at least to some extent, mirror the amount of energy people perceive to have at their disposal. Importantly, the present research specifies why people with a nonlimited theory experienced high vitality and why people with a limited theory lacked the energy to strive for their goals tenaciously. They did so not because they inherently have a particularly large or very small "willpower reservoir." People with a nonlimited theory got energy from doing things they like to do or that were important to them. In contrast, people with a limited theory did not feel energized during their activities because they lacked autonomous motivation.

The close association between autonomy and vitality implies that people who pursue controlled goals are likely to experience higher self-control affordances (e.g., Englert \& Bertrams, 2015; Muraven, Gagné, \& Rosman, 2008). The aversion toward working on a controlled task may inherently create additional self-control demands (i.e., having to overcome internal barriers) in addition to the challenges of the actual task (like studying for difficult exams). In addition to this increase in self-control demands, which makes goal progress less likely, the shift toward a limited theory about willpower found in the present studies is likely to further undermine people's self-regulation. As previous research shows, specifically when self-control demands are high, people with a limited willpower theory are prone to failure in their self-regulation (Job, Walton et al., 2015).

Furthermore, our results suggest that providing people who believe that their willpower is limited with more autonomy and freedom to choose the goals they want to pursue will result in enhanced vitality and, consequently, alter their theory about willpower. It therefore seems important to promote people's autonomy, for example, by creating autonomy supportive environments (Reeve, 2002).

The present results have implications for the broader research on autonomy. Previous research has repeatedly shown that autonomy is associated with positive effects during goal striving and self-control (Englert \& Bertrams, 2015; Milyavskaya et al., 2015; Silva et al., 2011). The present research suggests that autonomy regarding one specific goal or task can have consequences reaching beyond the context of this specific goal or task, by promoting the endorsement of a nonlimited theory. Beneficial effects of a nonlimited willpower theory have been documented for controlled type selfcontrol tasks in the laboratory (Job et al., 2010). A shift toward a nonlimited theory produced by autonomous motivation in one task might, at least in the short run, result in sustained self-control for another task in which controlled motivation prevails. However, as the present research suggests, repeatedly working on rather controlled tasks for a longer period of time might change a nonlimited theory about willpower back toward a limited theory.

These findings could be applied in different contexts. In the occupational context, for example, providing employees continuously with enhanced autonomy in specific workrelated tasks might promote performance even on tasks with restricted autonomy, where there is less room for individual decisions. In a similar vein, the results might also contribute to the understanding of so-called motivational spillover effects. Motivational spillover effects describe the transfer of autonomous motivation between two or more behaviors, such as from exercise behavior to eating self-regulation (Mata et al., 2009). However, willpower theories will have an effect on self-control performance most likely on tasks within the same domain, such as strenuous mental activities, as implicit theories are known to be domain-specific (Bernecker \& Job, 2017; Dweck, Chiu, \& Hong, 1995). Some people believe that strenuous mental activity is nonlimited while, simultaneously, they believe that repeatedly resisting temptation drains a limited resource. Analogously, research on goal pursuit documents that perceived autonomy is domain-(goal-) specific with high variability in autonomous motivation between the goals of an individual (Milyavskaya et al., 2015, see also Browman, Destin, \& Molden, 2017). The present research suggests that the intraindividual variability in goal motivation could be a reason for the domain-specificity of willpower theories. People might adopt a nonlimited theory in domains where they pursue goals autonomously (e.g., physical activity) and still 
have a limited theory in other domains (e.g., resisting temptation).

The finding that theories about willpower are influenced by autonomy and feelings of vitality raises further questions about the stability of implicit willpower theories. In this research, theories about willpower were still relatively stable over the examined time periods (4 months), replicating previous findings (Bernecker et al., 2017; Job et al., 2010). Nevertheless, our results show that willpower theories are, at least to a certain degree, malleable. Over their lifetime, people might experience phases of both relatively low as well as high autonomy. Consequently, they might be able to remember times when their willpower felt limited as well as times when it felt nonlimited. In accordance with this view, previous research has demonstrated that willpower theories can be manipulated by subtle procedures, such as biased questionnaires. Thereby, participants are subtly led to think of previous experiences where they felt that willpower is either more a limited versus nonlimited resource (Job et al., 2010; Miller et al., 2012). These findings suggest that both theories (limited and nonlimited) are potentially available to most people. Which theory is presently activated therefore depends, at least in part, on one's recent or most salient experiences with demanding tasks (as being energizing or draining).

\section{Understanding the Reciprocal Effect: Why People With a Nonlimited Theory Might Strive for More Autonomous Goals}

The present research focused on autonomous goal striving as an antecedent of a nonlimited theory about willpower. However, longitudinal Study 1 additionally revealed that implicit theories about willpower significantly predicted autonomous goal striving. This finding indicates that the effect between implicit theories about willpower and autonomous goal striving might be reciprocal. Why do people with a nonlimited theory strive for more autonomous goals? In their everyday life and work routine, people often have no choice but to prioritize controlled tasks. Whereas people with a limited theory might feel the need to rest once they have worked on their controlled tasks (Job, Bernecker, Miketta, \& Friese, 2015), people with a nonlimited theory might still have the energy to engage in personally meaningful activities. Thus, people who hold a nonlimited willpower theory might be able to work on personally important and intrinsically rewarding tasks more often in addition to their daily duties. In turn, they might experience more autonomy overall in their everyday lives.

The reciprocity between autonomous goal striving and a nonlimited willpower theory could therefore act as a selfreinforcing process that unfolds over time and results in high levels of autonomy, vitality, and a nonlimited theory. Of course, the mechanism might also shift toward a vicious cycle, in which a limited theory makes a person focus her activities on their mere duties, further reducing potential sources of vitality. This, in turn, might further reinforce the belief that willpower is a limited resource. On the contrary, it has been proposed that when people work on externally motivated tasks for some time, their attentional and motivational focus (automatically) shifts toward more intrinsically motivated activities (Inzlicht \& Schmeichel, 2012). Such a motivational shift back toward intrinsically rewarding activities could prevent escalation of controlled motivation and promote overall stability in willpower theories.

\section{Conclusion}

Whether people think about their willpower as limited or nonlimited reflects how much energy and vitality they recently experienced in their daily lives. This amount of energy is not related to a finite metabolic resource. It is the extent to which personal goals and daily tasks are approached with a sense of autonomy, whether people feel they are working on a specific task because they want to or because they have to, that creates differences in vitality and, in turn, affects people's beliefs about willpower. Therefore, the present research supports the notion that motivational processes, rather than finite metabolic resources, are pivotal for successful self-regulation.

\section{Declaration of Conflicting Interests}

The author(s) declared no potential conflicts of interest with respect to the research, authorship, and/or publication of this article.

\section{Funding}

The author(s) disclosed receipt of the following financial support for the research, authorship, and/or publication of this article: This research was supported by a grant from the Swiss National Science Foundation to Veronika Job (100014_159395).

\section{Supplemental Material}

Supplemental material is available online with this article.

\section{Notes}

1. Based on increasing meta-analytical and experimental evidence against the ego-depletion effect (e.g., Carter, Kofler, Forster, \& McCullough, 2015; Carter \& McCullough, 2014; Hagger et al., 2016; Molden et al., 2012; Randles, Harlow, \& Inzlicht, 2017), there is an ongoing debate whether the egodepletion effect is a real phenomenon.

2. In addition to the present studies, we conducted one experimental study, in which we tried to manipulate autonomous versus controlled motivation on willpower theories using an idiosyncratic approach. In this first study, we chose a manipulation which was held very global, asking participants about their goals in general. This led to extremely diverse responses in participants' reports. Consequently, we refined the manipulation for the present Study 3. Two further studies using the experimental procedure from Study 3 replicated the findings 
for different age groups (Job, Sieber, Rothermund, \& Nikitin, 2018). Taken together, all the studies conducted speak for the replicability of the relationship between autonomous motivation and willpower theories.

3. Previous research has documented that power for the indirect effect is affected when a mediator is either very close to the causal variable (proximal) leading to a large path $a$ or very close to the dependent variable (distal) leading to a large value for path $b$ (e.g., Kenny \& Judd, 2014). The present sensitivity calculations therefore assume an equal size for both paths.

4. The present study also included variables not related to the present research question. A full list of variables can be requested from the corresponding author.

5. Conducting the mediation analysis with vitality assessed in the first measurement also confirmed the mediation model, revealing a significant indirect effect of autonomous goal striving on implicit theories about willpower, $b=.02,95 \%$ CI $[0.00,0.05]$. We ran additional analyses to test whether autonomous motivation and controlled motivation have differential effects on the implicit theories about willpower (as suggested, e.g., by Milyavskaya, Inzlicht, Hope, \& Koestner, 2015). The results were not fully conclusive. In Study 1, the indirect effect was significant for both autonomous, $b=.10$, $95 \% \mathrm{CI}[0.03,0.21]$ and controlled motivation, $b=-.06,95 \%$ CI $[-0.13,-0.02]$. In Study 2 , the indirect effect was not significant when testing autonomous and controlled motivation separately. Autonomous and controlled motivation were correlated in Study 1, $r=-.18, p=.004$, but not in Study 2, $r=$ $-.10, p=.33$.

6. The research project also included an intervention aimed at changing participants' implicit theories about willpower. Of the 92 participants who filled in the questionnaires for the present study, a total of $n=35$ participants took part in the willpower intervention and $n=40$ participated in the control condition. As the intervention did not significantly affect the implicit theories about willpower, $t(73)=1.27, p=.209$, the intervention was not considered in the analyses.

7. The vitality measure is thought to reflect the core concept of vitality of being alive and energetic (Frederick \& Ryan, 1993). In German, "Frisch" is often used in everyday life to refer to being alive, energetic, and awake. In Study 3, the item "fresh" is part of the MDBF-scale, which we additionally employed to assess vitality (in addition to the vitality scale; Ryan \& Frederick, 1997). The correlation between the vitality scale and "fresh" shows a strong relationship between the two measures, $r=.66$.

8. The three studies were conducted with different samples, leading to different means in the implicit theories about willpower. In the first study, we assessed a German sample with a lot of adults aged above 54 years $\left(M_{\text {age }}=52.89, M_{d}=\right.$ 54 years). Research suggests that with increasing age, adults tend to agree more with a nonlimited theory about willpower (Job et al., 2018). Study 3 tested a sample of MTurk-Workers from the United States, where the median age was much lower $\left(M_{\text {age }}=36.50, M_{d}=34\right.$ years $)$. It therefore seems reasonable that the differences in the scores are due to the different age demographics of the samples assessed. The low stability in Study 2 could be due to the failed intervention (see Note 7).
9. We also assessed vitality with the MDMQ (Steyer, Schwenkmezger, Notz, \& Eid, 1997). Conducting the mediation analysis with the measure from the MDMQ led to similar results, revealing a significant indirect effect of autonomous goal striving on implicit theories about willpower, $b=0.50$, $95 \%$ CI, [0.33, 0.71].

10. The autonomy subscale from the balanced measure of psychological needs (BMPN, Sheldon \& Hilpert, 2012; e.g., While working on that task I was free to do things my own way.) was administered as an additional measure for autonomy. Participants provided their answers on a 6-point scale $(1=$ strongly disagree, $6=$ strongly agree $)(\alpha=.84, M=4.25, S D=1.25)$. A $t$ test concerning the experimental manipulation $(0=$ controlled, $1=$ autonomous) showed that participants in the autonomy condition $(M=4.82, S D=1.04)$ experienced significantly more autonomy than participants in the controlled-motivation condition $(M=3.73, S D=1.20), t(241)=7.53, p<.001, d=0.97$.

\section{References}

Barton, K. (2018). MuMIn: Multi-model inference (R Package Version, 1.40.4). Retrieved from https://CRAN.R-project.org /package $=$ MuMIn

Baumeister, R. F., Bratslavsky, E., Muraven, M., \& Tice, D. M. (1998). Ego depletion: Is the active self a limited resource? Journal of Personality and Social Psychology, 74, 12521265.

Bernecker, K., \& Job, V. (2015). Beliefs about willpower moderate the effect of previous day demands on next day's expectations and effective goal striving. Frontiers in Psychology, 6, Article 1496. doi:10.3389/fpsyg.2015.01496

Bernecker, K., \& Job, V. (2017). Implicit theories about willpower in resisting temptations and emotion control. Zeitschrift für Psychologie, 225, 157-166. doi:10.1027/21512604/a000292

Bernecker, K., Herrmann, M., Brandstätter, V., \& Job, V. (2017). Implicit theories about willpower predict subjective well-being. JournalofPersonality, 85,136-150.doi:10.1177/0165025415597550

Browman, A. S., Destin, M., \& Molden, D. C. (2017). Identityspecific motivation: How distinct identities direct self-regulation across distinct situations. Journal of Personality and Social Psychology, 113, 835-857. doi:10.1037/pspa0000095.supp

Brunstein, J. C., \& Maier, G. W. (2002). Das Streben nach persönlichen Zielen: Emotionales Wohlbefinden und proaktive Entwicklung über die Lebensspanne [Striving for personal goals: Emotional well-being and proactive development during the lifespan]. In G. Jüttemann \& H. Thomae (Eds.), Beltz-Taschenbuch Psychologie: Vol. 113. Persönlichkeit und Entwicklung (1st ed., pp. 157-190). Weinheim, Germany: Beltz.

Carter, E. C., Kofler, L. M., Forster, D. E., \& McCullough, M. E. (2015). A series of meta-analytic tests of the depletion effect: Self-control does not seem to rely on a limited resource. Journal of Experimental Psychology: General, 144, 796-815. doi:10.1037/xge0000083

Carter, E. C., \& McCullough, M. E. (2014). Publication bias and the limited strength model of self-control: Has the evidence for ego depletion been overestimated? Frontiers in Psychology, 5, Article 823. doi:10.3389/fpsyg.2014.00823

Clandinin, D. J. (1986). Classroom practice: Teacher images in action. London, England: Falmer. 
Clarkson, J. J., Otto, A. S., Hirt, E. R., \& Egan, P. M. (2016). The malleable efficacy of willpower theories. Personality and Social Psychology Bulletin, 42, 1490-1504. doi:10.1177/ 0146167216664059

Csikszentmihalyi, M., \& Larson, R. (1987). Validity and reliability of the experience sampling method. Journal of Nervous and Mental Disease, 175, 529-536.

Dweck, C. S., Chiu, C.-y., \& Hong, Y.-y. (1995). Implicit theories and their role in judgments and reactions: A word from two perspectives. Psychological Inquiry, 6, 267-285.

Emmons, R. A. (1986). Personal strivings: An approach to personality and subjective well-being. Journal of Personality and Social Psychology, 51, 1058-1068.

Englert, C., \& Bertrams, A. (2015). Autonomy as a protective factor against the detrimental effects of ego depletion on tennis serve accuracy under pressure. International Journal of Sport and Exercise Psychology, 13, 121-131. doi:10.1080/16121 97X.2014.932828

Fishbach, A., \& Ferguson, M. F. (2007). The goal construct in social psychology. In A. W. Kruglanski \& E. T. Higgins (Eds.), Social psychology: Handbook of basic principles (2nd ed., pp. 490-515). New York, NY: Guilford Press.

Frederick, C. M., \& Ryan, R. M. (1993). Differences in motivation for sport and exercise and their relations with participation and mental health. Journal of Sport Behavior, 16, 124-146.

Hagger, M. S., Chatzisarantis Nikos, L. D., Alberts, H., Anggono, C. O., Batailler, C., Birt, A. R., .. . Zwienenberg, M. (2016). A multilab preregistered replication of the ego-depletion effect. Perspectives on Psychological Science: A Journal of the Association for Psychological Science, 11, 546-573. doi: $10.1177 / 1745691616652873$

Hope, N. H., Milyavskaya, M., Holding, A. C., \& Koestner, R. (2016). The humble path to progress: Goal-specific aspirational content predicts goal progress and goal vitality. Personality and Individual Differences, 90, 99-107. doi:10.1016/j.paid.2015.10.038

Hormuth, S. E. (1986). The sampling of experiences in situ. Journal of Personality, 54, 262-293. doi:10.1111/j.1467-6494.1986. tb00395.x

Inzlicht, M., \& Schmeichel, B. J. (2012). What is ego depletion? Toward a mechanistic revision of the resource model of selfcontrol. Perspectives on Psychological Science: A Journal of the Association for Psychological Science, 7, 450-463. doi:10.1177/1745691612454134

Inzlicht, M., Schmeichel, B. J., \& Macrae, C. N. (2014). Why selfcontrol seems (but may not be) limited. Trends in Cognitive Sciences, 18, 127-133. doi:10.1016/j.tics.2013.12.009

Job, V., Bernecker, K., Miketta, S., \& Friese, M. (2015). Implicit theories about willpower predict the activation of a rest goal following self-control Exertion. Journal of Personality and Social Psychology, 109, 694-706. doi:10.1037/pspp0000042

Job, V., Dweck, C. S., \& Walton, G. M. (2010). Ego depletion-Is it all in your head? Implicit theories about willpower affect self-regulation. Psychological Science, 21, 1686-1693. doi:10.1177/0956797610384745

Job, V., Sieber, V., Rothermund, K., \& Nikitin, J. (2018). Age differences in implicit theories about willpower: Why older people endorse a nonlimited theory. Psychology and Aging, 33, 940-952. doi: 10.1037/pag0000285

Job, V., Walton, G. M., Bernecker, K., \& Dweck, C. S. (2015). Implicit theories about willpower predict self-regulation and grades in everyday life. Journal of Personality and Social Psychology, 108, 637-647. doi:10.1037/pspp0000014

Kasser, V., \& Ryan, R. M. (1999). The relation of psychological needs for autonomy and relatedness to vitality, well-being, and mortality in a nursing home. Journal of Applied Social Psychology, 29, 935-954.

Kenny, D. A. (2017). MedPower: An interactive tool for the estimation of power in tests of mediation [Computer software]. Retrieved from https://davidakenny.shinyapps.io/MedPower/

Kenny, D. A., \& Judd, C. M. (2014). Power anomalies in testing mediation. Psychological Science, 25, 334-339. doi:10.1177/0956797613502676

Kurzban, R., Duckworth, A., Kable, J. W., \& Myers, J. (2013). An opportunity cost model of subjective effort and task performance. Behavioral and Brain Sciences, 36, 661-679. doi:10.1017/S0140525X12003196

Mata, J., Silva, M. N., Vieira, P. N., Carraça, E. V., Andrade, A. M., Coutinho, S. R., . . . Teixeira, P. J. (2009). Motivational "spill-over" during weight control: Increased self-determination and exercise intrinsic motivation predict eating selfregulation. Health Psychology, 28, 709-716. doi.org/10.1037/ a0016764

Miller, E. M., Walton, G. M., Dweck, C. S., Job, V., Trzesniewski, K. H., McClure, S. M., \& Geng, J. J. (2012). Theories of willpower affect sustained learning. PLOS ONE, 7(6), e38680. doi:10.1371/journal.pone.0038680

Milyavskaya, M., Inzlicht, M., Hope, N., \& Koestner, R. (2015). Saying "no" to temptation: Want-to motivation improves selfregulation by reducing temptation rather than by increasing self-control. Journal of Personality and Social Psychology, 109, 677-693. doi:10.1037/pspp0000045

Molden, D. C., Hui, C. M., \& Scholer, A. A. (2016). Understanding self-regulation failure. In E. R. Hirt, J. Clarkson, \& L. Jia (Eds.), Self-regulation and Ego Control (pp. 425-459). San Diego, CA, US: Elsevier Academic Press. doi:10.1016/B9780-12-801850-7.00020-2

Molden, D. C., Hui, C. M., Scholer, A. A., Meier, B. P., Noreen, E. E., D'Agostino, P. R., \& Martin, V. (2012). Motivational versus metabolic effects of carbohydrates on self-control. Psychological Science, 23, 1137-1144. doi:10.1177/0956797612439069

Muraven, M., \& Baumeister, R. F. (2000). Self-regulation and depletion of limited resources: Does self-control resemble a muscle? Psychological Bulletin, 126, 247-259. doi:10.1037//00332909.126.2.247

Muraven, M., Gagné, M., \& Rosman, H. (2008). Helpful selfcontrol: Autonomy support, vitality, and depletion. Journal of Experimental Social Psychology, 44, 573-585. doi:10.1016/j. jesp.2007.10.008

Muraven, M., \& Slessareva, E. (2003). Mechanisms of self-control failure: Motivation and limited resources. Personality \& Social Psychology Bulletin, 29, 894-906. doi:10.1177/ 0146167203029007008

Nix, G. A., Ryan, R. M., Manly, J. B., \& Deci, E. L. (1999). Revitalization through self-regulation: The effects of autonomous and controlled motivation on happiness and vitality. Journal of Experimental Social Psychology, 35, 266-284.

Pinheiro, J., Bates, D., DebRoy, S., Sakar, D., \& R Core Team. (2017). nlme: Linear and nonlinear mixed effects models. $R$ package ver. 3.1-131. Retrieved from https:/CRAN.Rproject.org/package $=$ nlme. 
Preacher, K. J., \& Hayes, A. F. (2004). SPSS and SAS procedures for estimating indirect effects in simple mediation models. Behavior Research Methods, Instruments, \& Computers, 36, 717-731. doi:10.3758/BF03206553

Randles, D., Harlow, I., \& Inzlicht, M. (2017). A pre-registered naturalistic observation of within domain mental fatigue and domain-general depletion of self-control. PLOS ONE, 12(9), e0182980. doi:10.1371/journal.pone.0182980

R Core Team. (2017). R: A language and environment for statistical computing. Vienna, Austria: R Foundation for Statistical Computing. Available from http://www.R-project.org

Reeve, J. (2002). Self-determination theory applied to educational settings. In E. L. Deci \& R. M. Ryan (Eds.), Handbook of selfdetermination research (pp. 183-202). Rochester, NY: The University of Rochester Press.

Richardson, V. (1996). The role of attitudes and beliefs in learning to teach. In J. Sikula (Ed.), Handbook of research in teacher education (pp. 102-119). New York, NY: Macmillan.

Ryan, R. M., \& Deci, E. L. (2008). From ego depletion to vitality: Theory and findings concerning the facilitation of energy available to the self. Social \& Personality Psychology Compass, 2, 702-717. doi:10.1111/j.1751-9004.2008.00098.x

Ryan, R. M., \& Frederick, C. (1997). On energy, personality, and health: Subjective vitality as a dynamic reflection of wellbeing. Journal of Personality, 65, 529-565.

Salmon, S. J., Adriaanse, M. A., Vet, E., de Fennis, B. M., \& DeRidder, D. T. (2014). "When the going gets tough, who keeps going?" Depletion sensitivity moderates the ego-depletion effect. Frontiers in Psychology, 5, Article 647. doi:10.3389/ fpsyg.2014.00647

Savani, K., \& Job, V. (2017). Reverse ego-depletion: Acts of selfcontrol can improve subsequent performance in Indian cultural contexts. Journal of Personality and Social Psychology, 113, 589-607. doi:10.1037/pspi0000099

Schüler, J., Sheldon, K. M., Prentice, M., \& Halusic, M. (2016). Do some people need autonomy more than others? Implicit dispositions toward autonomy moderate the effects of felt autonomy on well-being. Journal of Personality, 84, 5-20. doi:10.1111/ jopy. 12133

Sheldon, K. M. (2002). The self-concordance model of healthy goal striving: When personal goals correctly represent the person. In E. L. Deci \& R. M. Ryan (Eds.), Handbook of self-determination research (pp. 65-86). Rochester, NY: University of Rochester Press.

Sheldon, K. M., \& Elliot, A. J. (1999). Goal striving, need satisfaction, and longitudinal well-being: The self-concordance model. Journal of Personality and Social Psychology, 76, 482-497.

Sheldon, K. M., \& Hilpert, J. C. (2012). The balanced measure of psychological needs (BMPN) scale: An alternative domain general measure of need satisfaction. Motivation and Emotion, $36,439-451$.

Sheldon, K. M., \& Kasser, T. (1995). Coherence and congruence: Two aspects of personality integration. Journal of Personality and Social Psychology, 68, 531-543. doi:10.1037/0022-3514.68.3.531

Sheldon, K. M., Ryan, R. M., Deci, E. L., \& Kasser, T. (2004). The independent effects of goal contents and motives on well-being: It's both what you pursue and why you pursue it. Personality and Social Psychology Bulletin, 30, 475-486. doi:10.1177/0146167203261883

Sheldon, K. M., Ryan, R. M., \& Reis, H. T. (1996). What makes for a good day? Competence and autonomy in the day and in the person. Personality and Social Psychology Bulletin, 22, 12701279. doi: $10.1177 / 01461672962212007$

Sieber, V., Schüler, J., \& Wegner, M. (2016). The effects of autonomy support on salivary alpha-amylase: The role of individual differences. Psychoneuroendocrinology, 74, 173-178. doi:10.1016/j.psyneuen.2016.09.003

Silva, M. N., Markland, D., Carraca, E. V., Vieira, P. N., Coutinho, S. R., Minderico, C. S., . . . Teixeira, P. J. (2011). Exercise autonomous motivation predicts 3-yr weight loss in women. Medicine \& Science in Sports \& Exercise, 43, 728-737. doi:10.1249/MSS.0b013e3181f3818f

Steyer, P., Schwenkmezger, P., Notz, M., \& Eid, M. (1997). Der Mehrdimensionale Befindlichkeitsfragebogen (MDBF) [The multidimensional mood questionnaire]. Zeitschrift für Klinische Psychologie und Psychotherapie, 31, 66-67. doi:10.1026//1616-3443.31.1.66

Thayer, R. E. (1997). The origin of everyday moods: Managing energy, tension, and stress. Oxford paperbacks Psychology. New York, NY: Oxford University Press.

Thayer, R. E., \& Moore, L. E. (1972). Reported activation and verbal learning as a function of group size (social facilitation) and anxiety-inducing instructions. The Journal of Social Psychology, 88, 277-287. doi:10.1080/00224545.1972.9918685 